\title{
A trial of nicotinamide in newly diagnosed patients with Type 1 (insulin-dependent) diabetes mellitus
}

\author{
H.P.Chase, N. Butler-Simon, S. Garg, M. McDuffie, S. L. Hoops and D. O'Brien \\ The Barbara Davis Center for Childhood Diabetes, Department of Pediatrics, University of Colorado Health Sciences Center, Denver, \\ Colorado, USA
}

\begin{abstract}
Summary. Various agents have been tried in subjects with newly diagnosed Type 1 (insulin-dependent) diabetes mellitus in an attempt to preserve Beta-cell function. In this double-blind study, nicotinamide or placebo were given for one year to 35 children and adolescents with newly-diagnosed Type 1 diabetes. All subjects were within six weeks of diagnosis and were between the ages of 6 and 18 years. Nicotinamide, a poly-(ADP-ribose) synthetase inhibitor, was given in a dose of $100 \mathrm{mg} / \mathrm{year}$ of age up to a maximum of $1.5 \mathrm{~g} /$ day. There were no initial differences between the 17 control and the 18 test subjects in relation to mean age, sex distribution, or severity at onset. Mean insulin dosages and
\end{abstract}

$\mathrm{HbA}_{1}$ values were similar for the two groups during the year of study. Fasting and glucagon-stimulated C-peptide levels were similar for the control and nicotinamide treated groups at the beginning and after 4 and 12 months. There were no differences in remission rates between the two groups. Nicotinamide, at this dosage, does not preserve residual insulin secretion in subjects with newly diagnosed Type 1 diabetes.

Key words: Type 1 (insulin-dependent) diabetes, nicotinamide, newly diagnosed, C-peptide, residual insulin secretion.
In recent years, the growing understanding of the basic pathology of Type 1 (insulin-dependent) diabetes mellitus has invited attempts to change the course of the disease. In one of these studies, nicotinamide was shown to reduce the incidence of glucosuria in female non-obese diabetic (NOD) mice [1], provided that it was given before overt disease appeared, and in another it prevented streptozocin induced diabetes in male Wistar rats [2]. Similarly, in conjunction with desferrioxamine, it prevented islet cell allograft rejection in the NOD mouse [3].

The primary action of nicotinamide is to inhibit the activation of poly-(ADP-ribose) synthetase following DNA strand breaks [4]. This inhibition will avoid the decrease in the cellular NAD content. The resultant increase in NAD content of Beta cells will favour proinsulin synthesis. Nicotinamide may also act directly as a hydroxyl ion scavenger [5] thus potentially modulating damage at two points.

The present study was undertaken to see if nicotinamide, given orally for one year, might bring about a significant alleviation of Type 1 diabetes in children and adolescents.

\section{Subjects and methods}

All patients who were newly-diagnosed as having Type 1 diabetes according to World Health Organization criteria [6] and who were 6 to 18 years of age were told of the study. Over an 18 month period, 35 of 67 subjects elected to participate within the required six weeks after diagnosis. There were no other exclusion criteria for admission to the study. Severity at onset was determined as previously described [7]. Subjects were randomly assigned to a treatment or to a placebo group in a double blind manner. Subjects or their guardians signed informed consent acceptances that had been approved by the University Human Subjects Committee.
Test subjects received a slow release nicotinamide preparation (Innovite, Inc. Tigard, Ore, USA) in an oral dose of $100 \mathrm{mg}$. age (years) ${ }^{-1} \cdot$ day $^{-1}$ up to a maximum of $1.5 \mathrm{~g} /$ day. This preparation was tested in NOD mice and it was confirmed that it had the ability to prevent diabetes as do conventional forms of the vitamin. The nicotinamide was administered two or three times per day with meals to maximize the accuracy of the dose using $250 \mathrm{mg}$ or $500 \mathrm{mg}$ tablets. Diabetes care was as previously described [8], with all subjects receiving 2 s.c. injections per day of human regular and NPH insulin, monitoring blood sugar 2 to 4 times daily, and following a sugar-restricted diet. Laboratory evaluations were carried out at the start of the study and after 4 and 12 months. These included $\mathrm{HbA}_{1}$ levels measured using ion exchange resin (Isolab Fast Hemoglobin Test System; Isolab, Inc., Akron, Ohio, USA) and liver function tests (transaminases, alkaline phosphatase and total bilirubin). Islet cell antibodies (ICA) were measured as previously described [9]. Blood was obtained for fasting C-peptide levels and for levels 6 min after an i.v. infusion of glucagon over $30 \mathrm{~s}$ of $20 \mu \mathrm{g} / \mathrm{kg}$ body weight up to a maximum of $1 \mathrm{mg}$. C-peptide levels were measured by RIA using the CYCLO-Trac SP 125/RIA Kit (Incstar Corp, Stillwater, Minn., USA), with a sensitivity of $0.03 \mathrm{pmol} / \mathrm{ml}$.

Compliance was measured by counting the number of tablets remaining in bottles at the three-monthly clinic visits. Reports from the subjects and their parents were also used in assessing compliance.

\section{Statistical analysis}

Statistical analyses were done using the SAS package [10]. The Student's $t$-test for two independent samples and the chi-square test were used.

\section{Results}

The nicotinamide group was composed of nine males and nine females, whereas 12 males and 5 females were in the control group ( $p>0.05$, chi-square test). The mean $( \pm 1 \mathrm{SD})$ age of the treatment subjects was $12.5 \pm 3.7$ years 
Table 1. Insulin doses at entry and after 4 and 12 months of nicotinamide or placebo treatment

\begin{tabular}{llll}
\hline Time of sampling & \multicolumn{2}{c}{ Insulin dose ${ }^{\mathrm{a}}$} & Significance $^{\mathrm{b}}$ \\
\cline { 2 - 3 } & Nicotinamide & Control & \\
\hline Baseline & $0.62 \pm 0.29$ & $0.65 \pm 0.20$ & $p>0.05$ \\
& $(18)^{\mathrm{c}}$ & $(17)$ & \\
4 months & $0.61 \pm 0.32$ & $0.41 \pm 0.28$ & $p>0.05$ \\
& $(18)$ & $(17)$ & \\
12 months & $0.75 \pm 0.23$ & $0.77 \pm 0.44$ & $p>0.05$ \\
& $(16)$ & $(15)$ & \\
& & &
\end{tabular}

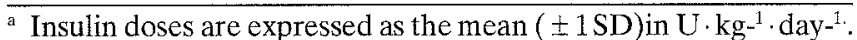

b Statistical significance was determined using the Student's $t$-test for two independent samples. ${ }^{\circ}$ The numbers in parentheses represent the number of subjects at each of the time periods

Table 2. $\mathrm{HbA}_{1}$ levels at entry and after 4 and 12 months of nicotinamide or placebo treatment

\begin{tabular}{llll}
\hline \multirow{2}{*}{$\begin{array}{l}\text { Time of } \\
\text { sampling }\end{array}$} & HbA $_{1}$ levels $^{\mathrm{a}}$ & & \\
\cline { 2 - 3 } Nicotinamide & Control & & Significance $^{\mathrm{b}}$ \\
\hline Baseline & $11.9 \pm 2.2$ & $11.6 \pm 2.1$ & $p>0.05$ \\
& $(18)^{\mathrm{c}}$ & $(17)$ & \\
\multirow{2}{*}{4 months } & $9.6 \pm 1.2$ & $9.4 \pm 2.3$ & $p>0.05$ \\
& $(18)$ & $(17)$ & \\
12 months & $10.6 \pm 1.9$ & $10.5 \pm 2.1$ & $p>0.05$ \\
& $(16)$ & $(15)$ & \\
\hline
\end{tabular}

a Values are expressed as the mean ( $\pm 1 \mathrm{SD})$ in \%. ${ }^{\mathrm{b}}$ Statistical significance was determined using the Student's $t$-test for two independent samples. ${ }^{c}$ Numbers in parentheses represent the number of subjects

Table 3. Plasma levels of C-peptide at entry and after 4 and 12 months of Nicotinamide or placebo treatment

\begin{tabular}{lll}
\hline Time of sampling & \multicolumn{2}{l}{ Plasma levels of C-peptide } \\
\cline { 2 - 3 } & $\begin{array}{l}\text { Control } \\
\text { subjects }\end{array}$ & \begin{tabular}{c} 
Nicotinamide $^{\mathrm{a}}$ treated subjects $^{\mathrm{c}}$ \\
\hline Baseline
\end{tabular} \\
$\begin{array}{l}\text { Fasting } \\
\text { Stimulated }\end{array}$ & $0.19 \pm 0.02$ & $0.26 \pm 0.04$ \\
4 months & $0.41 \pm 0.06$ & $0.51 \pm 0.06$ \\
Fasting & & \\
Stimulated & $0.19 \pm 0.03$ & $0.19 \pm 0.02$ \\
12 months & $0.50 \pm 0.12$ & $0.40 \pm 0.05$ \\
Fasting & & \\
Stimulated & $0.14 \pm 0.03$ & $0.16 \pm 0.05$ \\
\hline
\end{tabular}

a C-peptide levels are expressed as the mean ( \pm SEM) in pmol/ml.

b Plasma C-peptide levels 6 min after i.v. glucagon stimulation.

- Comparison of data between the control and nicotinamide-treated groups was not statistically significant ( $p>0.37$; Student's $t$-test) at all times (baseline, 4 months and 12 months)

(range $=6.0$ to 17.6 years) compared to $10.8 \pm 3.5$ years (range $=6.6$ to 16.8 years) for control subjects $(p>0.05$, Student's $t$-test). This was slightly higher than the usual mean age of onset due to the exclusion of children under age 6 years. Severity of onset was similar in both groups, with two subjects in each group having severe ketoacidosis $(\mathrm{pH}<7.10)$ and all others having a mild or moderate onset. Ketonuria at onset was present in 11 control and 12 test subjects. The mean duration $( \pm \mathrm{SEM})$ of diabetes prior to entering the study for the control group was $25.3 \pm 3.8$ days and for the nicotinamide group was $28.7 \pm 2.8$ days ( $p>0.05$; Student's $t$-test).
The mean insulin dose was similar in the treatment and control groups at all three time periods (Table 1). Likewise, mean $\mathrm{HbA}_{1}$ values were similar in the two groups at the three time periods (Table 2). Liver function tests remained normal in all subjects.

Fasting and glucagon-stimulated plasma C-peptide levels were similar $(p>0.05)$ between the nicotinamide and control groups at the beginning and after 4 and 12 months (Table 3 ). Only one subject did not increase C-peptide levels to $>0.1 \mathrm{pmol} / \mathrm{ml}$ after glucagon stimulation in the baseline samples. One nicotinamide-treated and three control subjects did not increase C-peptide levels to $>0.1 \mathrm{pmol} / \mathrm{ml}$ after 4 months $(p>0.05$; chi-square test). Four nicotinamide-treated and 7 control subjects did not increase C-peptide levels to $0.1 \mathrm{pmol} / \mathrm{ml}$ after 12 months ( $p>0.05$, chi-square test).

The ICA test was initially positive for 14 of 18 in the treatment group and for 14 of 17 in the control group. After 4 months, four of the nicotinamide group and two in the control group who were initially positive had become negative ( $p>0.05$; chi-square test). After 12 months, an additional four subjects in the control group and three subjects in the nicotinamide group who were positive initially and at 4 months were also negative.

Only one control subject (and none receiving nicotinamide) was able to discontinue insulin injections for seven days or longer without fasting or 2-h post-prandial blood glucose levels exceeding $7.25 \mathrm{mmol} / \mathrm{l}$.

\section{Discussion}

Nicotinamide has been shown to be effective in diminishing the occurrence of clinical diabetes in the female NOD mouse, where the Beta-cell destructive process is assumed to be autoimmune. However, the results of its use in humans have so far been equivocal. Vague et al. [11] first reported giving $3.0 \mathrm{~g} / \mathrm{day}$ in a double blind study to seven subjects aged $22.1 \pm 2.4$ years with nine control subjects. They showed a suggestive increase at 6 and 12 months in the proportion of patients no longer needing insulin and lower insulin requirements in the treated group at both times. In a slightly larger and somewhat older group of 11 treated patients and 12 control subjects [12], nicotinamide was given for nine months; but in this series the subjects had already been on insulin for 1-5 years before the trial was begun. Although there was no difference in insulin requirements at 6 or 9 months, $\mathrm{HbA}_{1}$ values were lower in the treated group at these times and C-peptide responses to glucagon were significantly better maintained $(p \leq 0.05)$ in the treatment group. In a smaller and slightly younger group, Mendola et al. [13] gave $1 \mathrm{~g} /$ day of nicotinamide for 45 days only. No differences were noted in mean insulin requirements or mean levels of $\mathrm{HbA}_{1}$ over a one year follow-up. C-peptide responses showed an initial significant improvement over the control group at 15 days but this effect was not sustained. More recently, Pozzilli, et al. [14] in a non-double blinded study showed small doses of nicotinamide successful in improving metabolic control in recent-onset Type 1 diabetes. They also did not find significant differences in basal or stimulated C-peptide values between control and nicotinamide-treated groups over one year of study. 
It is pertinent to examine the reasons why no differences were found between the treated and control groups in our study. Our sample was somewhat larger than in the earlier studies; but the mean age was ten or more years younger, which would fit with the concept that loss of islet cell function proceeds more rapidly in younger age groups [15]. In talking with the parents and the subjects and in counting tablets, motivation did not seem to be a problem. However, compliance has not been evaluated in any of the studies other than by monitoring tablet consumption. Urinary levels of nicotinamide could be monitored, but subjects could then increase compliance when they knew this was to be done. Dosage may be an issue, and Vague et al. $[11,12]$ used twice the dose used in our study. Also, the numbers in all of the clinical studies to date have been insufficient to detect significant effects of nicotinamide on preservation of Beta-cell function.

Two possibilities for the future are suggested by these results; the first is to obtain confirmation of the value of nicotinamide in the preclinical phase in humans [16]. It may be that in a stage of diabetes prior to insulin dependence, when islet cells are capable of greater insulin production, that nicotinamide might be more effective. The second possibility is to further explore its role for newly diagnosed patients when used in a higher dosage, or when used in conjunction with other approaches or immunomodifiers. These might include intensive insulin therapy [17], low dose cyclosporine A, prednisone or free radical scavengers, all of which might effect different stages of the insulitis.

No significant side effects have been encountered with the use of nicotinamide in any of the clinical studies reported in subjects with diabetes or other conditions [18]. It is inexpensive and freely available in health food stores in the United States. At the same time, there is evidence [19] that it is a co-carcinogen with alloxan and streptozotocin in rats, where it may cause benign islet cell tumours. A recent study by LeDoux et al. [20], on cultured rat insulinoma cells came to a more reassuring conclusion. While acknowledging the contention of Nomikos et al. [3], that inhibition of poly (ADP-ribose) synthetase might encourage oncogenesis, they demonstrated evidence for the alternate view, that the direct DNA chain breaks in the alloxan-induced model were actually diminished in the presence of nicotinamide.

In summary, the therapeutic role of nicotinamide in Type 1 diabetes still merits further evaluation at both the prediabetic stage and, in combined trials with other agents, at the beginning of the clinical phase.

Acknowledgements. Appreciation is expressed to Ms. A. Green for help in manuscript preparation. This study was supported in part by The Children's Diabetes Foundation at Denver and the General Clinical Research Centers Program of the Division of Research Resources, National Institutes of Health (No. RR-69).

\section{References}

1. Yamada K, Nonaka K, Hanafusa T, Miyazaki A, Toyoshima H, Tarui S (1982) Preventive and therapeutic effects of large-dose nicotinamide injections on diabetes associated with insulitis. Diabetes 31:749-753
2. Uchigata Y, Yamamoto H, Nagai H, Okamoto H (1983) Effect of poly (ADP-ribose) synthetase inhibitor administration to rats before and after injection of alloxan and streptozocin on islet proinsulin synthesis. Diabetes $32: 316-318$

3. Nomikos IN, Prowse SJ, Carotenuto P, Lafferty KJ (1986) Combined treatment with nicotinamide and desferrioxamine prevents islet cell allograft destruction in NOD mice. Diabetes 35 : 1302-1304

4. Okamoto H(1985) Molecular basis of experimental diabetes: degeneration, oncogenesis and regeneration of pancreatic B-cells of Islets of Langerhans. Bio Essays 2: 15-21

5. Wilson GL, Patton NJ, McCord JM, Mullins DW, Mossman BT (1984) Mechanisms of streptozotocin- and alloxan-induced damage in rat B cells. Diabetologia 27: 587-591

6. 1985 World Health Organization Criteria for Diabetes Mellitus Status (1985) Geneva, WHO Tech. Rep. Ser no. 727

7. Hamman RF, Cook M, Keefer S, Young WF, Finch JL, Lezotte D, McLaren B, Orleans M, Klingensmith G, Chase HP (1985) Medical care patterns at the onset of insulin-dependent diabetes mellitus: association with severity and subsequent complications. Diabetes Care 8 [Suppl 1]: 94-100

8. Chase HP (1985) Avoiding the short- and long-term complications of juvenile diabetes. Pediatr Rev 7: 140-149

9. Gleichmann H, Bottazzo GF (1987) Progress toward standardization of cytoplasmic islet cell-antibody assay. Diabetes 36 : $578-584$

10. SAS User's Guide (1985) Statistics version, 5th edn. Cary, NC:SAS Institute Inc.

11. Vague P, Vialettes B, Lassman-Vague V, Vallo JJ (1987) Nicotinamide may extend remission phase in insulin-dependent diabetes. Lancet I: 619-620

12. Vague P, Picq R, Bernal M, Lassman-Vague V, Vialettes B (1989) Effect of nicotinamide treatment on the residual insulin secretion in Type 1 (insulin-dependent) diabetic patients. Diabetologia $32: 316-321$

13. Mendola G, Casamitjana R, Gomis R (1989) Effect of nicotinamide therapy upon B-cell function in newly diagnosed Type 1 (insulin-dependent) diabetic patients. Diabetologia 32: 160-162

14. Pozzilli P, Visalli N, Ghirlanda G, Manna R, Andreani D (1989) Nicotinamide increases C-peptide secretion in patients with recent onset Type 1 diabetes. Diab Med 6: 568-571

15. The DCCT Research Group (1987) Effects of age, duration and treatment of insulin-dependent diabetes mellitus on residual beta-cell function: observations during eligibility testing for the diabetes control and complications trial (DCCT). J Clin Endocrinol Metab 65: 30-36

16. Elliott RB, Chase HP, Pilcher CC, Edgar BW (1988) Effect of nicotinamide in preventing diabetes (IDDM) in children. The immunology of diabetes, IXTH International Workshop, Melbourne, Australia, $p 18$ (Abstract)

17. Shah SC, Malone JI, Simpson ME (1989) A randomized trial of intensive insulin therapy in newly diagnosed insulin-dependent diabetes mellitus. N Engl J Med 320: 550-554

18. Hoffer A (1969) Safety, side effects and relative lack of toxicity of nicotinic acid and nicotinamide. Schizophrenia 1: 78-87

19. Yamagami T, Miwa A, Takasawa S, Yamamoto $H$, Okamoto $H$ (1985) Induction of rat pancreatic B-cell tumors by the combined administration of streptozocin or alloxan and poly (adenosine diposphate ribose) synthetase inhibitors. Cancer Res 45:1845-1849

20. LeDoux SP, Hall CR, Forbes PM, Patton NJ, Wilson GL (1988) Mechanisms of nicotinamide and thymidine protection from alloxan and streptozocin toxicity. Diabetes 37: 1015-1019

Received: 13 November 1989

and in revised form: 1 March 1990

Dr. H.P.Chase

Barbara Davis Center for Childhood Diabetes

University of Colorado Health Sciences Center

4200 East Ninth Avenue

Box B 140

Denver, Colorado 80262

USA 